\title{
Shiga Toxin Kills Epithelial Cells Isolated from Distal but not Proximal Part of Mouse Colon
}

\author{
Mari Kashiwamura, ${ }^{a}$ Kohta Kurohane, ${ }^{a}$ Takashi Tanikawa, ${ }^{a}$ Aya Deguchi, ${ }^{a}$ Daisei Miyamoto, ${ }^{b}$ and \\ Yasuyuki IMAI*,a \\ ${ }^{a}$ Laboratory of Microbiology and Immunology and the Global COE Program, University of Shizuoka School of \\ Pharmaceutical Sciences; and ${ }^{b}$ Department of Biochemistry, University of Shizuoka School of Pharmaceutical Sciences; \\ 52-1 Yada, Suruga-ku, Shizuoka, Shizuoka 422-8526, Japan. \\ Received May 2, 2009; accepted June 22, 2009; published online June 23, 2009
}

\begin{abstract}
Shiga toxins (Stxs) are major virulence factors produced by enterohemorrhagic Escherichia coli 0157:H7 colonizing the human and cattle intestines. We previously demonstrated that recombinant binding subunits (Stx1B) bound to the mucosal epithelium of the distal but not that of the proximal part of the mouse colon. Here we developed a method for isolating colon epithelial cells from the proximal and distal parts separately. Enrichment of epithelial cells was confirmed by the expression of cytokeratin. There was no difference in the epithelial cell purity between the proximal and distal colon preparations. The isolated epithelial cells from the distal colon were found to display binding sites for recombinant Stx1B whereas those from the proximal colon were not. Taking advantage of this single cell isolation, we examined the effect of Stx1 holotoxin on the epithelial cells. Consistent with the expression of the binding sites, Stx1 induced apoptosis of the epithelial cells from the distal but not those from the proximal colon. The results provide direct evidence that mouse colon epithelial cells are susceptible to Stx1 toxicity corresponding to the expression of binding sites for toxins.
\end{abstract}

Key words Shiga toxin; apoptosis; epithelial cell; distal colon; Escherichia coli O157:H7

Shiga toxins (Stxs) are virulence factors of enterohemorrhagic Escherichia coli (EHEC) strains such as serotype O157:H7. ${ }^{1)}$ There are two types of Stx, Stx1 and Stx2, which are associated with human diseases with life-threatening complications, including hemolytic-uremic syndrome (HUS) and central nervous system involvement. Stx holotoxin (70 kDa) consists of a $32 \mathrm{kDa}$ cytotoxic subunit (A subunit) and a pentamer of $7.7 \mathrm{kDa}$ binding subunits (B subunit).,3) The B subunits of Stx 1 and Stx 2 both bind to carbohydrate ligand globotriaosylceramide $\left(\mathrm{Gb}_{3}, \quad \mathrm{Gal} \alpha 1 \rightarrow 4 \mathrm{Gal} \beta 1 \rightarrow\right.$ $4 \mathrm{Glc} \beta 1 \rightarrow 1 \mathrm{Cer}$ ), also known as CD77, on human germinal center B cells and Burkitt's lymphoma cells., ${ }^{4,5}$

In children with HUS, the most severe and earliest damage is found in the left and transverse portions of the colon (distal parts of the colon). ${ }^{6}$ In mouse system, we have previously demonstrated that the recombinant B subunit of Stx1 (Stx1B) avidly binds to the epithelium of distal but not proximal parts of the colon by means of immunohistochemical methods. ${ }^{7)}$ Recent study also demonstrated a restricted binding of Stx2 to the distal colonic epithelium in rats. ${ }^{8)}$ However, it is not clear whether the binding of Stx holotoxin provokes epithelial cell damage. In this study, we isolated viable epithelial cells from the mouse proximal and distal colon separately. We compared the binding of Stx1B and susceptibility to Stx1 holotoxin using isolated epithelial cells from different parts of the colon.

\section{MATERITALS AND METHODS}

Mice Specific-pathogen-free female CD-1 (ICR) mice were obtained from Japan SLC Inc. (Shizuoka, Japan), and were used between 6 and 8 weeks of age. Animal care and experiments were undertaken in compliance with the ethical guidelines for the animal facilities of the University of Shizuoka.

Reagents Preparation of recombinant binding subunits of Stx1 (Stx1B) and digoxigenin-labeled Stx1B (DIG-Stx1B) were performed as described previously. ${ }^{9}$ Stx 1 holotoxin was kindly provided by Dr. Shinji Yamazaki (Osaka Prefecture University, Osaka, Japan). ${ }^{3)}$ Fluorescein isothiocyanate-labeled sheep anti-digoxigenin Fab fragments (FITC-antiDIG), rhodamine-labeled sheep anti-digoxigenin Fab fragments (rhodamine-anti-DIG), 4',6-diamidino-2-phenylindole dihydrochloride (DAPI), and an in situ cell death detection kit (fluorescein) were purchased from Roche Diagnostics (Tokyo, Japan). Polyclonal rabbit anti-cow cytokeratin (wide spectrum screening) was purchased from Dakocytomation (Glostrup, Denmark), and Texas Red-goat anti-rabbit immunoglobulin $\mathrm{G}(\mathrm{IgG})(\mathrm{H}+\mathrm{L})$ from Vector (Burlingame, California, U.S.A.). Dulbecco's modified Eagle's medium (DMEM) was purchased from Nissui Pharmaceuticals (Tokyo, Japan), and fetal bovine serum (FBS) from HyClone (South Logan, Utah, U.S.A.). Penicillin G and L-glutamine were purchased from MP Biomedicals (Solon, Ohio, U.S.A.), Triton X-100 from Tokyo Chemical Industries (Tokyo, Japan), and streptomycin sulfate and gentamicin from Wako Pure Chemicals (Osaka, Japan). Percoll was purchased from GE Healthcare Biosciences (Uppsala, Sweden), $N$-(2-hydroxyethyl)piperazine- $N^{\prime}$-2-ethanesulfonic acid (HEPES) from Nacalai Tesque (Kyoto, Japan), and 2-mercaptoethanol (2$\mathrm{ME}$ ) and bovine serum albumin (BSA) from Sigma (St. Louis, Missouri, U.S.A.). Recombinant human epidermal growth factor (EGF) and insulin-transferrin-selenium supplement (ITS) were purchased from Invitrogen (Carlsbad, California, U.S.A.), and mouse collagen type IV and Matrigel from Japan Becton Dickinson (Tokyo, Japan).

Isolation and Purification of Epithelial Cells Mice were killed under ether anesthesia and then their colons were removed. Each colon was divided into proximal $(<3 \mathrm{~cm}$ below the cecum) and distal $(>5 \mathrm{~cm}$ below the cecum) parts. The colon segments were flushed with phosphate-buffered saline (PBS) containing $100 \mathrm{U} / \mathrm{ml}$ penicillin $\mathrm{G}, 100 \mu \mathrm{g} / \mathrm{ml}$ 
streptomycin sulfate and $25 \mu \mathrm{g} / \mathrm{ml}$ gentamicin to remove feces. The colon segments were then everted, ligated at one end, and inflated by injecting PBS according to the published method. ${ }^{10,11)}$ The opposite end was then ligated. The segments were agitated in $30 \mathrm{ml}$ of PBS containing $0.02 \%$ ethylenediaminetetraacetic acid (EDTA), $100 \mathrm{U} / \mathrm{ml}$ penicillin $\mathrm{G}$, $100 \mu \mathrm{g} / \mathrm{ml}$ streptomycin sulfate and $25 \mu \mathrm{g} / \mathrm{ml}$ gentamicin in $50-\mathrm{ml}$ tubes using a vortex mixer, with 10 cycles of mixing for $15 \mathrm{~s}$ each. The cells released from the colon segments were transferred to $15-\mathrm{ml}$ tubes, and then centrifuged for $10 \mathrm{~min}$ at $200 \times \boldsymbol{g}$ at $4{ }^{\circ} \mathrm{C}$. Each cell pellet was suspended in DMEM containing $5 \mathrm{~mm}$ HEPES ( $\mathrm{pH}$ 7.4). The cell suspension was then centrifuged for $30 \mathrm{~min}$ through a $5 \%, 15 \%$, $40 \%$ discontinuous Percoll gradient in $5 \mathrm{~mm}$ HEPES-DMEM for $30 \mathrm{~min}$ at $560 \times \mathbf{g}$ at $4{ }^{\circ} \mathrm{C}$. Epithelial cells were recovered from the $5 \%$ and $15 \%$ Percoll interface, and then were washed by centrifugation for $10 \mathrm{~min}$ at $200 \times \boldsymbol{g}$ in DMEM at $4{ }^{\circ} \mathrm{C}$.

Immunofluorescence The purified cells were suspended in PBS containing $0.02 \%$ EDTA, and then were forced to become attached to MAS-coated glass slides (Matsunami Glass, Osaka, Japan) by means of a cytocentrifuge. The cells were fixed in acetone for $30 \mathrm{~s}$ at room temperature and then air-dried. Only in the case of cytokeratin detection was involved, cells were permeabilized with PBS containing $0.1 \%$ Triton X-100 for $15 \mathrm{~min}$ at room temperature, and then washed three times with PBS. Nonspecific binding sites were blocked with $3 \%$ BSA in PBS for $10 \mathrm{~min}$ at room temperature. The cells were incubated with either rabbit anti-cow cytokeratin (undiluted) or DIG-Stx1B $(5 \mu \mathrm{g} / \mathrm{ml}$ in $3 \%$ BSAPBS) for $30 \mathrm{~min}$ at room temperature. After washing three times with PBS, each sample was incubated with $100 \mu \mathrm{l}$ of the respective secondary reagent diluted in 3\% BSA-PBS, Texas Red-goat anti-rabbit IgG $(5 \mu \mathrm{g} / \mathrm{ml})$ containing DAPI $(0.01 \mu \mathrm{g} / \mathrm{ml})$, or rhodamine anti-DIG $(2 \mu \mathrm{g} / \mathrm{ml})$ containing DAPI for $30 \mathrm{~min}$ at room temperature. After washing three times with PBS, the cells were mounted with Gel/Mount (Biomeda, Foster City, California, U.S.A.). Cell-associated fluorescence was observed under a fluorescence microscope (BX-51; Olympus, Tokyo, Japan). The numbers of cytokeratin-positive cells, cells positive for Stx1B binding, and total cells (nuclear staining with DAPI) were determined using an objective lens of $20 \times$ magnification. At least 100 cells per field and three fields for slide were counted.

Flow Cytometry Purified epithelial cells $\left(5 \times 10^{5}\right)$ suspended in $100 \mu \mathrm{l}$ of PBS containing $0.1 \% \mathrm{NaN}_{3}$ and $0.1 \%$ BSA (PBS-BSA) were incubated with DIG-Stx1B (10 $\mu \mathrm{g} / \mathrm{ml}$ ) for $30 \mathrm{~min}$ at $4{ }^{\circ} \mathrm{C}$. After washing three times by centrifugation in PBS-BSA for $5 \mathrm{~min}$ at $4{ }^{\circ} \mathrm{C}$, the cells were incubated in $100 \mu \mathrm{l}$ of FITC-anti-DIG $(0.4 \mu \mathrm{g} / \mathrm{ml}$ in PBSBSA). After $30 \mathrm{~min}$ incubation at $4^{\circ} \mathrm{C}$, the cells were washed twice in PBS-BSA. Cells were passed through a piece of nylon mesh and then analyzed with a flow cytometer (EPICS XL; Beckman Coulter, Fullerton, California, U.S.A.). The results were analyzed using FlowJo software (version 8.0.3; Tree Star, Ashland, Oregon, U.S.A.).

TUNEL Assay Epithelial cells were suspended in DMEM supplemented with $10 \%$ FBS, ITS $(150 \mathrm{ng} / \mathrm{ml}$ insulin, $82 \mathrm{ng} / \mathrm{ml}$ transferrin, and $0.1 \mathrm{ng} / \mathrm{ml}$ sodium selenite), $10 \mathrm{ng} / \mathrm{ml} \mathrm{EGF,} 100 \mathrm{U} / \mathrm{ml}$ penicillin, $100 \mu \mathrm{g} / \mathrm{ml}$ streptomycin, $10 \mathrm{~mm}$ HEPES (pH 7.4), $50 \mu \mathrm{m}$ 2-ME and $2 \mathrm{~mm}$ L-glutamine.
Cells were added to 16-well chamber slides (Nalge Nunc, Rochester, New York, U.S.A.) that had been coated with either mouse collagen type IV or Matrigel. The cells were cultured for $16 \mathrm{~h}$ at $37^{\circ} \mathrm{C}$ under a humidified atmosphere of $5 \%$ $\mathrm{CO}_{2} / 95 \%$ air. The cells were then cultured in the presence or absence of $0.1 \mathrm{ng} / \mathrm{ml}$ of Stx 1 for an additional $24 \mathrm{~h}$ at $37^{\circ} \mathrm{C}$. Stx1-treated or control cells were fixed with $4 \%$ formaldehyde in PBS for $30 \mathrm{~min}$ at room temperature, washed once with PBS, and then permeabilized with $0.1 \%$ Triton $\mathrm{X}-100$ in $0.1 \%$ sodium citrate buffer $\left(\mathrm{pH}\right.$ 6.9) for $2 \mathrm{~min}$ at $4{ }^{\circ} \mathrm{C}$. After washing twice with PBS, the cells were incubated with $3 \%$ BSA-PBS for $15 \mathrm{~min}$ at room temperature. DNA fragmentation was detected by means of the terminal deoxynucleotydyl transferase (TdT)-mediated dUTP nick end labeling (TUNEL) reaction using the in situ cell death detection kit (fluorescein) according to the manufacturer's instructions. After washing twice with PBS, the cells were incubated with rabbit anti-cow cytokeratin (undiluted) to counterstain epithelial cells for $30 \mathrm{~min}$ at room temperature. After washing twice with PBS, the cells were incubated with $5 \mu \mathrm{g} / \mathrm{ml}$ Texas Red-goat anti-rabbit IgG for $30 \mathrm{~min}$ at room temperature. After washing three times with PBS, the cells were mounted using Gel/Mount. We determined whether each cytokeratinpositive cell exhibited a TUNEL signal under a fluorescence microscope. We counted more than 100 cytokeratin-positive cells in each well (triplicate culture) using an objective lens of $20 \times$ magnification. The apoptosis index is expressed as the percentage of the TUNEL-positive cells per number of cytokeratin-positive cells examined.

Statistical Analysis Data are expressed as means \pm standard deviation (S.D.). Statistical significance was analyzed by means of Student's $t$-test. $p$ values of $<0.05$ were considered to be statistically significant.

\section{RESULTS AND DISCUSSION}

We separately prepared epithelial cells from the proximal and distal colon by Percoll density gradient centrifugation. Their viability was more than $80 \%$ (trypan blue dye exclusion). When cells were stained with anti-cytokeratin (a marker for epithelial cells) followed by counterstaining with DAPI (nuclear staining), the majority of cells have cytokeratin in the cytoplasm regardless of the proximal or distal colon (Figs. 1A, B). Cytokeratin was expressed in $87 \pm 3 \%$ (mean \pm S.D.) of cells from the proximal colon and $91 \pm 2 \%$ of cells from the distal colon, respectively, in three independent experiments. The results indicated successful isolation of epithelial cells from mouse colon.

The epithelial cells isolated from the proximal or distal colon were incubated with DIG-Stx1B followed by incubation with rhodamine anti-DIG antibodies. DAPI was used for nuclear staining. Epithelial cells isolated from the proximal colon did not (Fig. 1C), whereas ones from the distal colon did reveal binding sites for DIG-Stx1B (Fig. 1D). DIGStx1B binding was observed in $3.1 \pm 2.9 \%$ (mean \pm S.D., $n=6$ ) of cells from the proximal colon and $73.3 \pm 5.5 \%$ of cells from the distal colon, respectively. This is consistent with our previous results using an immunohistochemical method involving frozen sections. ${ }^{7)}$

We also compared the binding of DIG-Stx1B to unfixed cells by means of flow cytometry. Cells were incubated with 


\section{Cytokeratin}
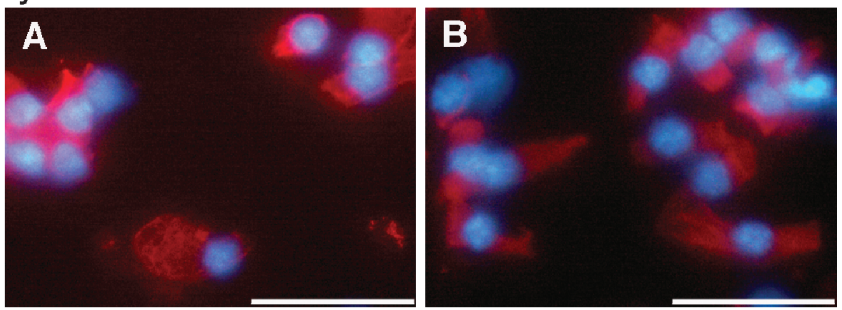

StxB1
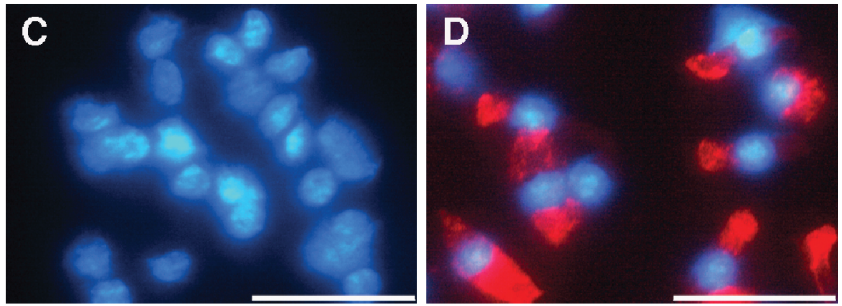

Stx1 holotoxin (TUNEL)

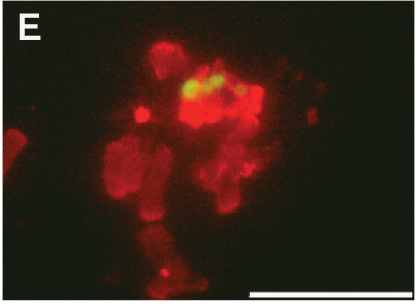

proximal colon

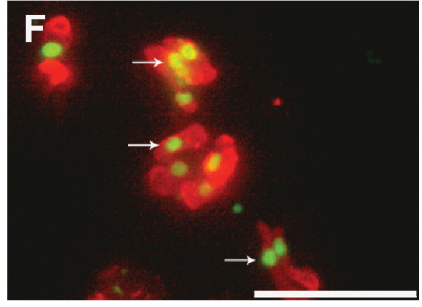

distal colon
Fig. 1. Representative Fluorescent Micrographs of Epithelial Cells Isolated from the Proximal and Distal Mouse Colon

Cells enriched by Percoll density gradient centrifugation from proximal $(<3 \mathrm{~cm}$ below the cecum; panels $\mathrm{A}, \mathrm{C}$ and $\mathrm{E})$ and distal $(>5 \mathrm{~cm}$ below the cecum; panels $\mathrm{B}, \mathrm{D}$ and F) parts of the mouse colon were examined as follows: (A, B) Cells were stained with anti-cytokeratin (red) and then counter-stained with DAPI (blue). The majority of cells expressed cytokeratin regardless of the part of the colon. (C, D) Cells were incubated with DIG-Stx1B plus rhodamine-anti-DIG (red) and then counter-stained with DAPI (blue). Cells isolated from the distal (D), but not the proximal part, of the colon (C) carried binding sites for Stx1B. (E, F) Cells were cultured on collagen type IVcoated slides and then treated with Stx 1 holotoxin $(0.1 \mathrm{ng} / \mathrm{ml})$ for $24 \mathrm{~h}$ at $37^{\circ} \mathrm{C}$. The TUNEL method (green) was employed for the detection of apoptotic cells and then the cells were counterstained with anti-cytokeratin (red). Nuclei with fragmented DNA were more abundant in the cells from the distal colon (F) after exposure to Stx1. Arrows indicate examples of apoptotic nuclei $(\mathrm{F})$. An objective lens of $40 \times$ magnification was used and bars represent $50 \mu \mathrm{m}$.
DIG-Stx1B followed by FITC-anti-DIG antibodies, and fluorescence signals above nonspecific ones (FITC-anti-DIG alone) as well as background ones (no DIG-Stx1B and no FITC-anti-DIG) were evaluated. In the case of cells from the proximal colon, only a slight shift in the fluorescence intensity was observed above the nonspecific level and the background (Fig. 2A). In contrast, a marked shift was observed for cells from the distal colon (Fig. 2B). Similar results were consistently obtained from three independent experiments.

Viable cell isolation from mouse colon allowed us to examine whether Stx1 holotoxin exhibits selective cytotoxicity toward epithelial cells from the distal colon. After exposure to Stx1 holotoxin $(0.1 \mathrm{ng} / \mathrm{ml})$, apoptosis was assayed by the TUNEL method (Figs. 1E, F). In the case of epithelial cells from the distal colon, the number of nuclei reflecting DNA fragmentation was significantly higher $(p<0.0005)$ upon Stx1 treatment compared with in cells without Stx1 treatment (Fig. 2C). In contrast, there was no difference in the number of apoptotic cells among epithelial cells from the proximal colon between with and without the Stx 1 treatment $(p>0.05)$. The viability of primary-isolated epithelial cells was somewhat low after 2-d-culture, however, the background was similar for cells from the proximal and distal colon. When cells were cultured on Matrigel-coated slides, Stx1-induced apoptosis was also selectively observed for epithelial cells from the distal colon (data not shown).

In conclusion, we found that epithelial cells isolated from the mouse distal, but not proximal, colon carried binding sites for Stx1B. Stx1 holotoxin was found to induce apoptosis of the epithelial cells of the distal, but not the proximal, colon. The results provide direct evidence that the binding of Stx to colon epithelial cells can result in cell damage.

Acknowledgments We thank Dr. Shinji Yamazaki (Osaka Prefecture University, Sakai, Osaka, Japan) for providing the Stx1 holotoxin. This work was supported in part by a Grant-in-Aid (18659033) from and the COE Program in the 21 st Century of the Japan Society for the Promotion of Science.

\section{REFERENCES}

1) Nataro J. P., Kaper J. B., Clin. Microbiol. Rev., 11, 142-201 (1998).
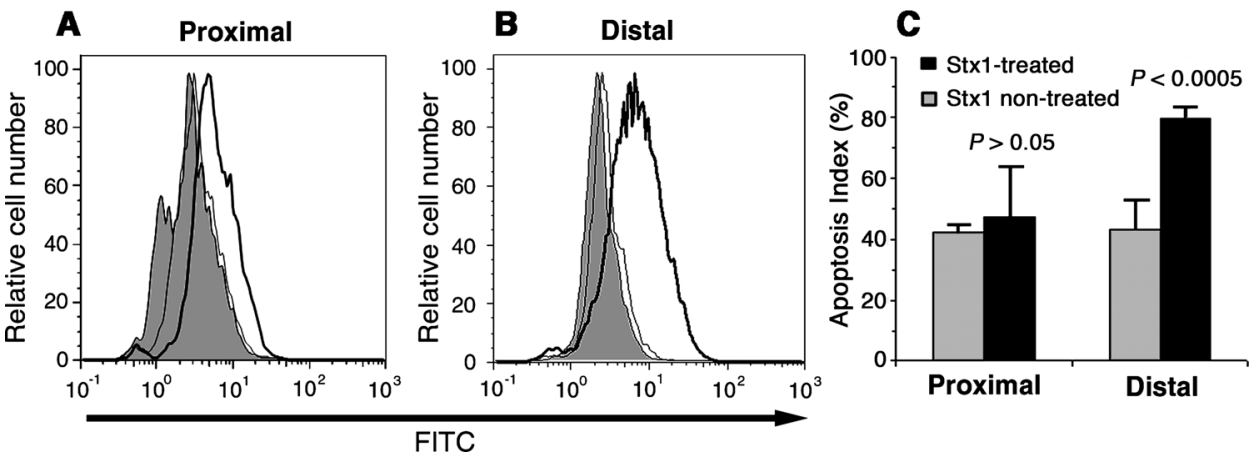

Fig. 2. Selective Binding of Stx1B and Selective Toxicity of Stx1 Holotoxin to Viable Epithelial Cells of the Distal Colon

(A, B) Unfixed epithelial cells were incubated with or without DIG-Stx1B followed by FITC-anti-DIG, and then analyzed with a flow cytometer. The abscissa of histograms represents the fluorescence intensity on a log scale. Histograms of cells incubated with DIG-Stx1B plus FITC-anti-DIG (thick lines), FITC-anti-DIG alone (thin lines), and nothing (thin lines with shaded areas) are presented for cells from the proximal (A) and distal (B) colon, respectively. (C) Epithelial cells were cultured in the presence or absence of Stx 1 $(0.1 \mathrm{ng} / \mathrm{ml})$ for $24 \mathrm{~h}$ at $37^{\circ} \mathrm{C}$. DNA fragmentation was detected by the TUNEL method, and epithelial cells were identified with anti-cytokeratin. Apoptosis index (ordinate) is the percentage (means \pm S.D. for six independent experiments) of TUNEL-positive cells out of all the cytokeratin-positive cells. 
2) Calderwood S. B., Auclair F., Donahue-Rolfe A., Keusch G. T., Mekalanos J. J., Proc. Natl. Acad. Sci. U.S.A., 84, $4364-4368$ (1987).

3) Takao T., Tanabe T., Hong Y.-M., Shimonishi Y., Kurazono H., Yutsudo T., Sasakawa C., Yoshikawa M., Takeda Y., Microb. Pathog., 5, 357-369 (1988)

4) Lingwood C. A., Trends Microbiol., 4, 147-153 (1996).

5) St. Hilaire P. M., Boyd M. K., Toone E. J., Biochemistry, 33, 1445214463 (1994).

6) Murray K. F., Patterson K., Pediatr. Dev. Pathol., 3, 232-239 (2000).

7) Imai Y., Fukui T., Kurohane K., Miyamoto D., Suzuki Y., Ishikawa T.,
Ono Y., Miyake M., Infect. Immun., 71, 985-990 (2003).

8) Zotta E., Lago N., Ochoa F., Repetto H. A., Ibarra C., Pediatr. Nephrol., 23, 559-567 (2008).

9) Miyashita S., Matsuura Y., Miyamoto D., Suzuki Y., Imai Y., Glycoconj. J., 16, 697-705 (1999).

10) Kearsey J. A., Stadnyk A. W., J. Immunol. Methods, 194, 35-48 (1996).

11) Stadnyk A. W., Dollard C., Issekutz T. B., Issekutz A. C., Gut, 50, $629-635$ (2002). 